\title{
Physico-Chemical Evaluation of Pavalasilasathu Parpam, a Marine based Traditional Siddha Drug used in Leucoderma and Infectious Conditions
}

\author{
Mekala1, Sathish $^{2}$, Arul Amuthan ${ }^{3^{*}}$
}

\begin{abstract}
${ }^{1}$ Department of Nanju Noolum Maruthuva Neethi Noolum, National Institute of Siddha, Chennai, INDIA. ${ }^{2}$ Department of Sattam Saarntha Maruthuvamum Nanju Noolum, Sri Sairam Siddha Medical College, Chennai, INDIA. ${ }^{3}$ Department of Pharmacology, Melaka Manipal Medical College and Center for Integrative Medicine and Research, Manipal University, INDIA.
\end{abstract}

\begin{abstract}
Background: Pavalasilasathu parpam (PSP) is one of the marine derived drugs used in Siddha Medicine for the treatment of leucoderma and respiratory infections. So far, no studies have been done on this drug. Objective: To prepare pavalasilasathu parpam as per the traditional Siddha literature and to evaluate its chemical changes during drug preparation processes. Materials and Methods: First, Suddhi (purification) process of pavalam (coral) and silasathu (selenite) were done by individually processed with Aloe vera juice and tender coconut water respectively. The chemical change in coral and selenite before and after the purification process was analyzed using Fourier transform infrared spectroscopy (FTIR) and inductively coupled plasma optical emission spectroscopy (ICP-OES). Then, coral and selenite were ground well together with Cissus quadrangularis juice for 12 hours and subjected to calcination process. The obtained whitish ash was called as PSP. The physico-chemical property of PSP was analyzed using ash values, FTIR, ICP-OES and Scanning Electron Microscope (SEM). Amount of heavy metal was quantified. Results: The procedure Suddhi reduced the amount of sodium, iron, calcium, phosphorous, sulfur and magnesium in coral and selenite. Particle size ranges between 30-80 $\mu \mathrm{m}$. Heavy metals like mercury, lead, arsenic and cadmium were below detectable level. Amount of calcium, phosphorous and sulphur were $225 \mathrm{mg}, 10 \mathrm{mg}$ and $22 \mathrm{mg}$ in $1 \mathrm{~g}$ of PSP. FTIR showed the peaks for the presence of six organic compounds. Conclusion: Pavalasilasathu parpam does not have heavy metals, but contains calcium, phosphorous and Sulphur with few organic phytochemicals derived from Cissus quadrangularis, which was used during the preparation process.
\end{abstract}

Key words: Corel, selenite, Siddha, Ayurveda, Bhasma, Pavalam, Marine, Cissus quadrangularis, Leucoderma.

Citation: Mekala, Sathish, Amuthan A. Physico-Chemical Evaluation of Pavalasilasathu Parpam, a Marine based Traditional Siddha Drug used in Leucoderma and Infectious Conditions. Int J Pharmacol and Clin Sci. 2015;4(3):44-47.

\section{INTRODUCTION}

Siddha Medicine, one of the oldest Indian traditional medicines describes variety of marine derived drugs including fishes, shells, sponges and corals. Recently number of researches is actively conducted in the drug discovery from marine based drugs. Pavalasilasathu parpam (PSP) is one of such marine based Siddha drug mainly used in the treatment of leucoderma, diabetes mellitus, certain infectious conditions such as tuberculosis, respiratory infections, syphilis and venereal infections. This drug is administered at the dose of $100 \mathrm{mg} /$ day with ghee. Pavalam (coral), silasathu (selenite), Aloe vera, Cissus quadrangularis and tender coconut water are the five ingredients in this preparation. ${ }^{[1]}$ Usually, preparation of mineral based Siddha drugs is a lengthy procedure and believed that the

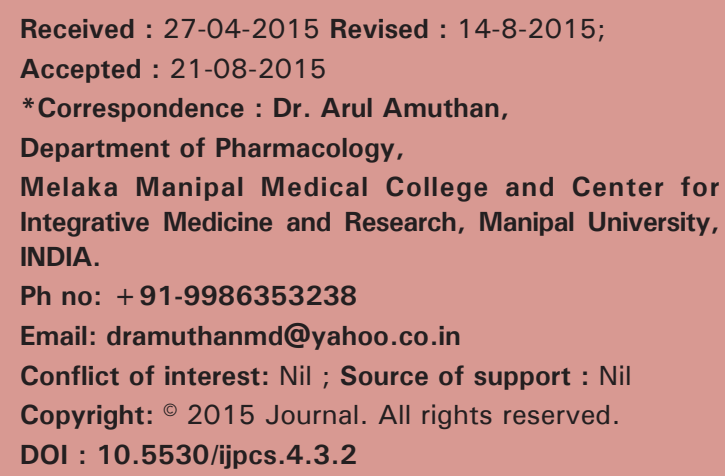


combinatorial and transmutation changes occur during the processing. Literature survey revealed that the chemical changes during the processing and chemical composition of this drug have not been reported. Thus, the objective of current study was to evaluate the chemical changes during the drug preparation process and also to evaluate the phyisco-chemical properties of pavalasilasathu parpam.

\section{MATERIALS AND METHODS}

All the procedures of pre-drug preparation and drug preparation were strictly based on the Siddha literature.

${ }^{[1]}$ Raw materials were purchased from authorized Siddha raw material shop in Chennai, India. Siddha literature emphasizes the purification process (Suddhi) of raw materials which are used to prepare the mineral based drugs. In this study, coral and selenite have been purified using herbals.

\section{Pre-drug preparation (purification) and chemical analysis: ${ }^{[1]}$}

Coral was purified using Aloe vera juice as follows; Coral was encapsulated in a clean unbleached cotton cloth, tied to a stick and kept inside a clay pot containing one liter of Aloe vera juice without immersing. The pot was heated for one hour allowing the coral to be exposed to vapor arises from the pot. After that, the encapsulated coral was taken out, washed in fresh water and dried. Now, the coral is called as purified coral.

Selenite was purified using tender coconut water. Selenite was placed in a clay pot filled with tender coconut water till the selenite was fully immersed. Heat was applied till the tender coconut water evaporated completely. Then the selenite was washed with fresh water and dried. Now the selenite was called as purified selenite.

The chemical changes in coral and selenite before and after the purification process was assessed by Fourier transform infrared spectroscopy (FTIR) and inductively coupled plasma optical emission spectroscopy (ICP-OES).

\section{Drug preparation and checmial analysis}

Purified coral (35 gm) and purified selenite (35 gm) were powdered then ground with the juice of Cissus quadrangularis for 12 hours in the traditional stone mortar. Then, the semisolid paste was made into small round cakes which were dried in sunlight. Dried cakes were taken placed into a mud pot and closed with another mud pot with sealing the gap by cotton cloth dipped in wet clay. This was subjected to calcination process (pudam in Siddha). After calcination, the powdered medicine known as Pavalasilasathu parpam was collected from the lower pot and ground well. The particle size of the drug was analyzed using Scanning electron microscope (SEM). Physic-chemical properties were evaluated using FT-IR and ICP-OES.

\section{RESULTS}

\section{Changes due to purification process}

Aloe vera treatment in coral showed reduction in sodium, calcium, phosphorous, sulphur, magnesium and iron. Tender coconut water treatment in selenite also showed reduction of the same elements (Table 1).

FT-IR showed that there was no change in the organic functional groups of coral even after the purification process (Aloe vera treatment). All the stretches and bending vibrations in the graph were within the range. Thus, there

\begin{tabular}{|c|c|c|c|c|c|}
\hline \multirow[b]{2}{*}{ Elements } & \multicolumn{2}{|c|}{ Pavalam (coral) in mg } & \multicolumn{2}{|c|}{ Silasathu (selenite) in mg } & \multirow{2}{*}{$\begin{array}{l}\text { pavalasilasathu } \\
\text { parpam in } \mathrm{mg}\end{array}$} \\
\hline & $\begin{array}{c}\text { Before } \\
\text { purification }\end{array}$ & $\begin{array}{c}\text { After } \\
\text { purification }\end{array}$ & $\begin{array}{c}\text { Before } \\
\text { purification }\end{array}$ & $\begin{array}{c}\text { After } \\
\text { purification }\end{array}$ & \\
\hline Mercury & BDL & BDL & BDL & BDL & $\mathrm{BDL}$ \\
\hline Lead & BDL & BDL & $\mathrm{BDL}$ & BDL & $\mathrm{BDL}$ \\
\hline Cadmium & $\mathrm{BDL}$ & BDL & BDL & $\mathrm{BDL}$ & BDL \\
\hline Arsenic & BDL & BDL & $\mathrm{BDL}$ & BDL & BDL \\
\hline Sodium & 32.13 & 12.31 & 52.32 & 23.01 & 2.31 \\
\hline Calcium & 512.75 & 492.75 & 743.37 & 723.15 & 224.51 \\
\hline Phosphorus & 23.08 & 13.17 & 13.27 & 3.56 & 10.49 \\
\hline Sulphur & 5.33 & 4.23 & 225.84 & 220.47 & 22.48 \\
\hline Magnesium & 15.43 & 6.79 & - & - & 1.74 \\
\hline Iron & 10.07 & 4.23 & - & - & 0.14 \\
\hline
\end{tabular}

[BDL-Below detectable level] 


\begin{tabular}{|c|c|}
\hline Parameters & Values \\
\hline $\mathrm{pH}$ at $25^{\circ} \mathrm{c}(1: 10$ ratio $)$ & $7.5-8$ \\
\hline Total ash value & 12.10 \\
\hline Acid insoluble ash & 0.75 \\
\hline Water Soluble ash & 4.6 \\
\hline Loss on drying at $105^{\circ} \mathrm{C}$ & $3.2 \mathrm{~g}$ \\
\hline Alkalinity ash $\mathrm{CaCo}_{3}$ & 11.2 \\
\hline
\end{tabular}

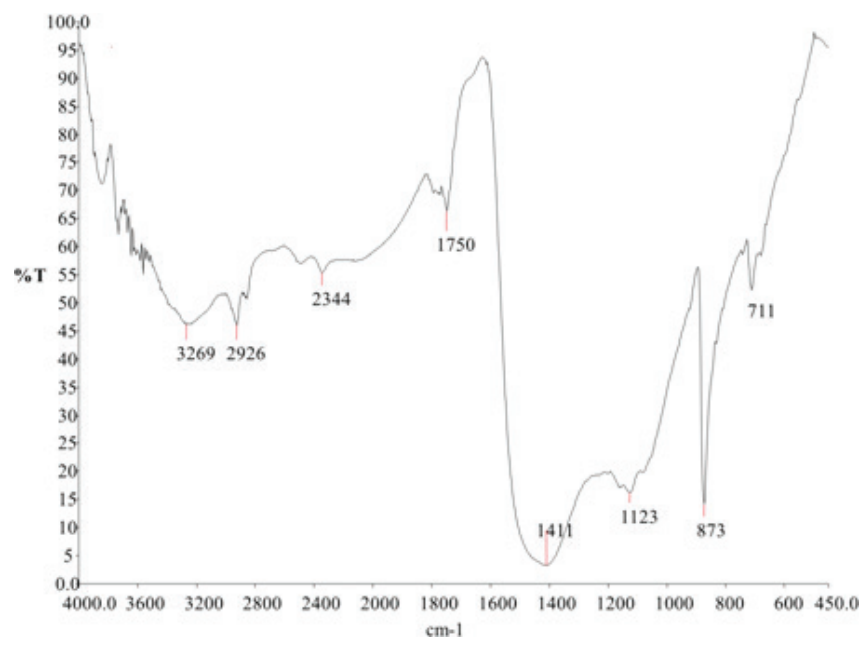

Figure 1: Fourier transform infrared spectroscopy (FTIR) graph of coral before the purification process

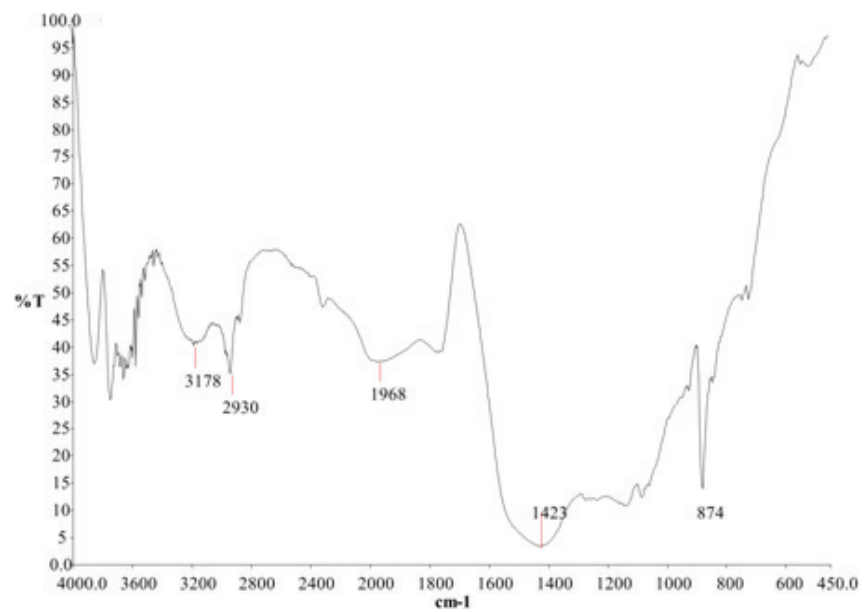

Figure 2: Fourier transform infrared spectroscopy (FTIR) graph of coral after the purification process

is no structural change in the functional groups during the suddhi process in coral. (Figure 1,2). The same was observed in case of selenite also. Thus, the treatment of Aloe vera and tender coconut ater has not added any new organic compound to coral and selenite during the purification process (Figure 3, 4).

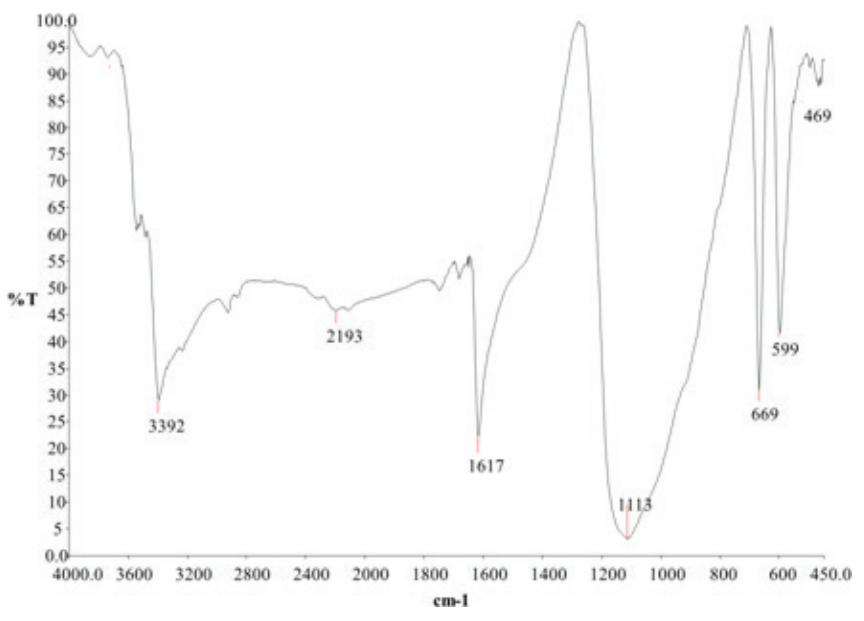

Figure 3: Fourier transform infrared spectroscopy (FTIR) graph of selenite before the purification process

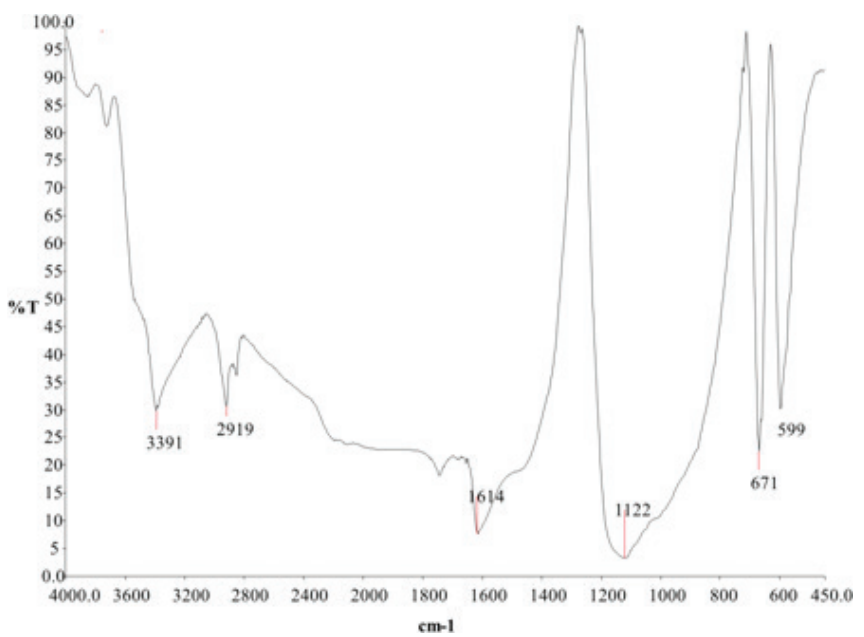

Figure 4: Fourier transform infrared spectroscopy (FTIR) graph of seenite after the purification process

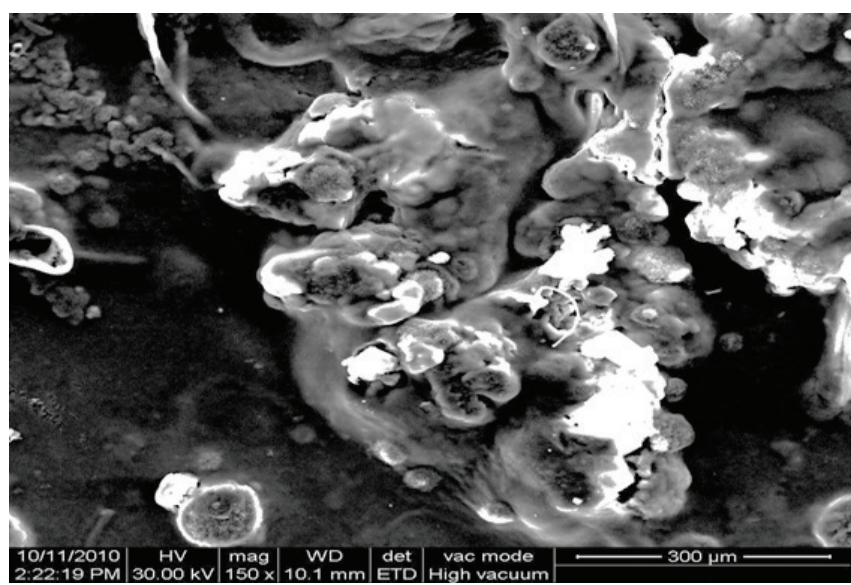

Figure 5: Scanning electron microscope (SEM) picture of pavalasilasathu parpam 


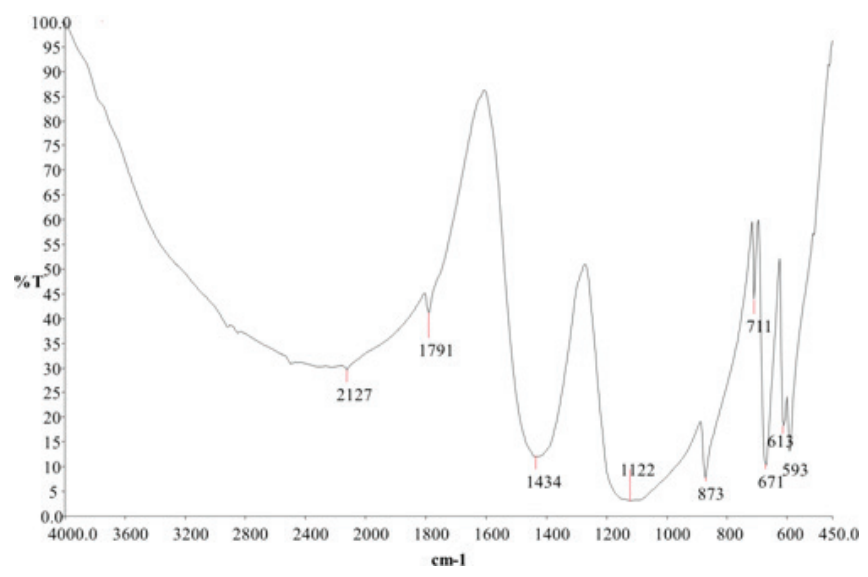

Figure 6: Fourier transform infrared spectroscopy (FTIR) graph of pavalasilasathu parpam

\section{Physico-chemical properties of pavalasilasathu parpam}

The particle size of the PSP was 30 to $80 \mu \mathrm{m}$ and the agglomeration of particles could be seen due to repeated cycle of heat application during purification and calcinations processes (Figure 5).

Table 1 shows that calcium is the major inorganic component of the drug. Table 2 gives the physical properties of the drug, which showed that the PSP is alkaline.

FTIR of PSP showed the peaks for the presence of more than six heat stable organic compounds, which were derived from coral and selenite. Peak 613 has been derived from Cissus quadrangularis as it is the addition after the processing with Cissus quadrangularis. These findings clearly reveal that the herbal used to prepare pavalasilasathu parpam has donated one active organic compound to the drug (Figure 6).

\section{DISCUSSION}

Traditional Siddha medicine always follows the purification (suddhi) process before preparing any drugs. The raw materials; be it a herbal or mineral or metal must undergo this process, which is believed that there is a removal of impurities, thus become less toxic. In our study, certain inorganic elements have been reduced in coral and selenite after the purification process. There was no functional group was added. Our study also confirmed that absence of heavy metals in this drug. Study revealed that the drug possess calcium as a major element along with minor sodium, phosphorus, sulphur, magnesium and iron. There are six heat stable organic groups present in the drug among them one is derived from Cissus quadrangularis. This drug is being used in leucoderma and infectious conditions especially respiratory infections including tuberculosis. The leucoderma is due to the deficiency in the melanin synthesis of skin. The melanin promotion activity of Cissus quadrangularis has been already reported in prior study. Earlier studies have demonstrated the antimicrobial activity of coral and Cissus quadrangularis against various microorganisms, which might be responsible for the antibacterial activity. ${ }^{[2-4]}$

Detailed studies are required to evaluate the importance of "Suddhi" (purification of raw drugs) in Siddha drug preparation technique, which may reveal the scope for combinatorial chemical modulation by traditional methods in pharmaceutical industry. Since the chemical composition is mainly depend on the herbals, which might contain varied amount of phytochemicals in response to different climate or different geological location, similar studies have to be repeated by using herbals collected from different locations and the variations in chemical composition have to be further documented. ${ }^{[5]}$

Pavalasilasathu parpam is a marine based Siddha mineral drug contains calcium as a major component along with sodium, phosphorus, sulphur, magnesium, iron and six heat stable organic compounds. Further studies are required to identify the active compounds and to create scientific evidence for the claim of using PSP for the treatment of leucoderma, diabetes mellitus, respiratory infections and tuberculosis.

\section{ACKNOWLEDGEMENT}

NIL

\section{REFERENCES}

1. Pillai CK. Kannusamy paramparai vaidyam (Tamil). B. Rathna Nayakkar \& Sons Publishers, Chennai, India. 2006. P.388.

2. Rao GV, Annamalai T, Mukhopadhyay T, Madhavi MSL. Chemical constituents and melanin promotion activity of Cissus quadrangularis. Research Journal of Chemical Sciences. 2011;1(2):25-9.

3. Radjasa OK, Wiese J, Sabdono A, Imhoff JF. Corals as source of bacteria with antimicrobial activity. Journal of Coastal Development. 2008;11(3):121-30.

4. Murthy KNC, Vanitha A, Swamy MM, Ravishankar GA. Antioxidant and antimicrobial activity of Cissus quandrangularis L. J Med Food. 2003;6(3):99-105.

5. Sathish R, Murugesan R, Amuthan A. Chemical Standardization of mega sanjeevimaathirai, a herbometallic Sidda drug. International Journal of Pharmaceutical Sciences Review and Research. 2012;13(2):35-8. 